\title{
Relevance: An Interdisciplinary and Information Science Perspective
}

\author{
Howard Greisdorf \\ School of Library and Information Science \\ University of North Texas
}

hfg0001@aol.com

\begin{abstract}
Although relevance has represented a key concept in the field of information science for evaluating information retrieval effectiveness, the broader context established by interdisciplinary frameworks could provide greater depth and breadth to on-going research in the field. This work provides an overview of the nature of relevance in the field of information science with a cursory view of how cross-disciplinary approaches to relevance could represent avenues for further investigation into the evaluative characteristics of relevance as a means for enhanced understanding of human information behavior.
\end{abstract}

Keywords: relevance, information science, information retrieval, information evaluation, degrees of relevance

\section{Introduction}

Relevance from a historical perspective has grown and expanded into a variety of interdisciplinary scholarly environments as an extension of thematic precedents evolving mainly from philosophical underpinnings. There are many variations on the concept of "relativism" as initially portrayed by the Greek philosophers, Protagorus and Gorgias, and later embedded into more modern movements espoused by William James and John Dewey. Most of these frameworks generally describe a theme that teaches us that what is known is dependent on the knowing subject (O'Neill, 1960).

The seminal work of Alfred Schutz is one of the best examples of a paradigmatic shift from philosophical discussions of relativism toward the social theory aspects of relevance. Although first printed in 1932, its value as a theoretical framework for relevance was not evident until the publication of his translated collected works in the 1960s and the eventual compilation of previously unpublished papers and lectures under the title Reflections on the Problem of Relevance (Schutz, 1970). Schutz's tripartite conceptualization of relevance into topical, interpretive and motivational relevance provided an approach for investigating the nature, manifestations and effects of this selective function of the mind.

Material published as part of this journal, either on-line or in print, is copyrighted by the publisher of Informing Science. Permission to make digital or paper copy of part or all of these works for personal or classroom use is granted without fee provided that the copies are not made or distributed for profit or commercial advantage AND that copies 1) bear this notice in full and 2) give the full citation on the first page. It is permissible to abstract these works so long as credit is given. To copy in all other cases or to republish or to post on a server or to redistribute to lists requires specific permission and payment of a fee. Contact Editor@inform.nu to request redistribution permission.

\section{Information Science Research: Information Retrieval}

Also during the 1960 s, a movement emerged that identified relevance as an evaluative tool for resolving problems associated with measuring the effectiveness of automated information systems. Various definitions of relevance, including the following, set the tone for ongoing research in the field of information science:

- a measure of information conveyed by a document relative to a query (Goffman, 1964).

- the criterion used to quantify the phenomenon involved when individuals (users) judge the relationship, utility, importance, degree of match, fit, proximity, appropriateness, closeness, pertinence, value or bearing of documents or document representations to an information requirement, need, question, statement, description of research, treatment, etc. (Rees, 1966)

These, and other early definitions, generated further explorations of relevance as a theoretical concept in information science, while other disciplines pursued relevance from differing perspectives.

For 30 years there has been no practical substitute for the concept of relevance as a criterion measure for quantifying the effectiveness of information retrieval (IR) systems (Rees, 1966). The fuzziness surrounding the nature of relevance has led to confusion in identifying appropriate criteria, measures, measuring instruments and methodology. In the context of a user's interaction with an IR system, "relevance is a psychological predicate that describes his acceptance or rejection of a relation between the meaning or content of a document and meaning or content of a question" (Taube, 1965). It is the rela- 
tionship, not the acceptance or rejection, that most studies have ignored. Saracevic (1975) and Schamber, Eisenberg and Nilan (1990) focused attention on "why" users accepted or rejected, instead of looking at the relationships of meanings. When relevance is represented, it is not a fine absolute judgment; it is in terms of comparative and gross absolute judgments. It is these intuitions of relevance that must be accounted for, not the simple presence or absence of relevance, but the degrees of relevance (Sperber \& Wilson, 1986).

This approach to relevance as relativism is not to be equated with ambiguity. "A person chooses for himself that alternative in a dichotomized construct through which he anticipates the greater possibility for extension and definition of his system" (Kelly, 1955). While the construct of black versus white is composed of mutually exclusive alternatives (just as relevant versus irrelevant is so composed), this does not preclude the use of the construct in a relativistic manner. Thus more grayness versus less grayness as a further abstraction of the construct black versus white is equivalent to partially relevant versus partially not relevant in relation to the construct of relevant versus irrelevant (not relevant). One value derived from accepting this relativistic approach to regions of relevance may help to differentiate experts from novices in their approach to resolving information needs. Experts can relatively easily integrate and organize new information by filling gaps in their knowledge when provided with partial or even distorted information (Sternberg, 1996). Novices, however, when presented with partially relevant information may not be able to fill in such gaps, and may actually change their understanding of their problem and/or change their problem definition (Spink \& Greisdorf, 1997; Spink, Greisdorf \& Bateman, 1998).

This concept of degrees of relevance is certainly not new to the literature. Hillman (1964) in agreement with earlier statements of Bar-Hillel (1958) stated that degrees of relevance must be considered in defining a weaker notion of relatedness in terms of documents, queries and index terms. That same discussion had Fairthorne (1958) bothered with the possibility of denying what he called the "excluded middle." Wilson (1973) took the same issue a step further in his discussion of situational relevance by admitting the desirability of recognizing degrees of relevance, but leaving it to others to identify how it should be measured. Wallis and Thom (1996) also agree that not only is it necessary to retrieve all relevant or partially relevant material, but that degrees of relevance are not a simple thing to express.

The argument stressing the importance and understanding of degrees of relevance is not without critics. Cooper (1971) provides an elaborate definition of relevance which "admits to no degrees of relevance;" while Tiamyu and Ajiferuke (1988) take a holistic approach and argue the concept of total relevance. These denials to the existence of degrees or regions of relevance, however, have been minimal. Those who admit to such regions of relevance without specifically stating them further perpetuate this discussion. O' Connor (1967) calls for a definite distinction by stating that "documents retrieved to satisfy a clearly formulated request should be kept separate from additional documents volunteered as a result of reading between the lines of a request."

In one of the well-cited studies in the field of information science, Saracevic, Kantor, Chamis and Trivison (1988) actually posed a definition for this middle region in the relevance debate. They indicate "partially relevant" as any document considered only somewhat, or in some part, related to the question or to any part of the question. Pao (1993) and Su (1994) also used a relevant, partially relevant, and not relevant methodology. In most cases, however, even though users and/or judges were able to conceptualize a meaningful difference between relevant and partially relevant documents, the experimental results were combined, collapsed, or grouped into a single category of "relevant" for the purpose of analysis.

Schamber (1994) identifies that information scientists have failed to reach consensus in answering "how" relevance judgments should be measured, and that dilemma is made perfectly clear by looking at a variety of studies in the field. Foskett (1972) said relevance is impossible to quantify, yet Goffman (1964) contributed an elaborate formulation entitled “on relevance as a measure." Eisenberg (1988) thought magnitude estimation was the answer. Park (1993) thought degrees of relevance encompassed a wide range requiring no a priori definition of relevance. Howard (1994) utilized a 13point relevance scale and Gluck (1996) used both fivecategory and two-category relevance scales. Brooks (1997) created a horizontal semantic distance in multidimensional space to identify what he described as the "relevance aura," while Mizzaro (1998) sought to measure relevance along four dimensions.

The measurement problem persists and a workable unifying framework is needed to bring future work in relevance research into an arena where all participants are on solid ground. The answer may lie in distinguishing the true measurement of separation between relevance and irrelevance. With rare exception, however, human judgment and decision behavior has been found to be sub-optimal consisting of large differences in the way people make judgments and decisions. Most researchers, however, do not perform analyses on aggregated data because they believe that the patterns present in aggregated data are poor characterizations of any of the individuals studied (Milech \& Finucane, 1998). 
With so much attention directed at the nature, manifestations and effects of individual user interactions with IR systems, there has been a tendency to miss concepts related to group interactions as a whole. In the area of relevance studies, most of the focus has centered on the identification of user attributes and criteria for evaluating items retrieved from an IR system (e.g. Barry and Schamber, 1998). In addition, the search for just the right balance of cognitively influenced aspects that define a user's ability to make relevance judgments has been approached from a variety of directions without much success in unifying the theoretical concepts associated with relevance, including cognitive modeling (Daniels, 1986; Belkin, 1990; Ellis, 1992; Harter, 1992; Ingwersen, 1996) satisfaction (Gluck, 1996; Thong \& Yap, 1996), value (Su, 1998), task (Allen, 1996; Belkin et. al., 1990), utility (Bates, 1996), pertinence (Kemp, 1974; Howard, 1994), and situation (Wilson, 1973).

When Caudra and Katter (1967) identify relevance as a "black box" and Janes (1994) perpetuates that notion with the "big black question mark," it becomes apparent that any approach to IR evaluation that encompasses the concept of relevance may necessitate dealing with a variety of overlaps, interactions and contradictions that will tend to confound attempts at explaining individual relevance behavior.

Integral with the evaluation problem is an examination of relevance judgment frequency distributions. Several studies, while seeking to explore different aspects of relevance, provided data that yielded distributions of relevance judgments that displayed certain unique bi-modal characteristics. Work by Rees and Schultz (1967), Saracevic (1969) and Janes (1991) all found similar distributions with a high number of judgments at each extreme (not rele-

vant/relevant) and a scattering of judgments in lesser numbers in the middle of the distribution. This characteristic nature of relevance judgment distributions was summarized by Janes (1993), but stopped short with a conclusion that this phenomenon may only be a statistical artifact. Considering that this bi-modality of relevance frequency distributions can only occur in the absence of strictly dichotomous judgments (relevant vs. not relevant), clarification as to the nature of the middle range of these judgments needs validation if these distributions are not just artifacts in the relevance judging process.

Spink and Greisdorf (1997) provided further evidence for the existence of the middle range that plays an important role for users in their early stages of seeking information on a particular problem and in creating changes in the user's information problem or question during the information seeking process. The middle range of relevance was expanded by Spink, Greisdorf and Bateman (1998a) in a three-dimensional spatial model of relevance that defines the manifestations of this middle region as consisting of partially relevant and partially not relevant judgments. Additional support for the nature of relevance frequency distributions is provided by Spink, Bateman and Greisdorf (1998b) in an investigation of successive searching behavior with evidence that search episodes early in the information seeking process contribute more partially relevant judgments than in later searches on the same problem. Further work investigating the middle regions of partial relevance has produced a taxonomy of end-user descriptions of partially relevant and partially not relevant judgments that identifies the middle regions of relevance as a dimension that consists of combinations of both positive and negative levels of relevance (Greisdorf \& Spink, 1999; Spink \& Greisdorf, forthcoming).

\section{Other Interdisciplinary Approaches to Relevance}

From perspectives in reasoning, necessity and logic, the work of Piaget surrounding genetic psychology and epistemology also provides a conceptual treatment of relevance. For Piaget, the logical concept of relevance introduces an important bridge between meaning and implication (Overton, 1990). In that context, relevance is a condition used to distinguish a genuine implication between antecedent and consequence from a weaker form of relationship. From this logical epistemological approach to relevance, implications for investigation in communication and cognitive arenas become evident.

The work of Sperber and Wilson (1986) provides a detailed approach to the study of human communication based on the fundamental idea that communicated information comes with a guarantee of relevance. With Sperber and Wilson's definitions of relevance, prior underpinnings from philosophy, psychology, logic and information science begin to emerge as a synthesis of meaning and understanding for this enigmatic, yet important, concept. Three key points are made that include:

- Relevance is a relation between an assumption and a context;

- Relevance is a matter of degree;

- Relevance can be represented in terms of comparative judgments and gross absolute judgments.

Considering that communication implies discourse, conceptual frameworks in that realm also help to expand the field of investigation surrounding relevance. As a model of cognition for accessibility to information Morrow and Greenspan (1989) state that relevance arises from the interplay between perspective, topic and focus at both global and local levels of discourse and that perceived relevance is derived from the comprehension achieved during such interplay at various levels. 


\section{Relevance}

This ongoing conceptualization of relevance across interdisciplinary boundaries continues to emerge, refine itself, and point to a variety of models and frameworks that recognize relevance as an important variable in relation to human information behavior. Representing this cursory overview on the importance of relevance across interdisciplinary bounds is, by no means, an exhaustive approach to this subject. Further research will uncover relevance as the underlying framework in a variety of theoretical approaches such as alternative reliable process theory (Goldman, 1986), adaptation level theory (Helson, 1971), Anderson and Belnap's entailment logic (Ricco, 1986), analogical argument (Copi, 1982) and implications for linguistic semantics (Carston \& Uchida, 1997). These are but a few examples of how relevance perspectives have emerged across a variety of scholarly disciplines in an attempt to describe, explain and predict a concept that engenders more than a simple dichotomy of choice.

By recognizing the value of these diverse interdisciplinary perspectives, identifying their common denominators, and synthesizing higher order frameworks for ongoing investigation can provide greater depth and breadth for relevance theory, and its value for enhancing theoretical approaches in information science, philosophy, logic, epistemology, psychology, communication and cognition.

\section{References}

Allen, B. L. (1996). Information tasks: Toward a user-centered approach to information systems. New York, NY: Academic Press.

Bar-Hillel, Y. (1958). Summary of Area 6 Discussion. Proceedings of the International Conference on Scientific Information, Washington, DC. (pp.1402).

Barry, C. L. \& Schamber, L. (1998). Users' criteria for relevance evaluation: A cross-situational comparison. Information Processing \& Management, 34(2/3), 219-236.

Bates, M. J. (1996). Document familiarity, relevance and Bradford's Law: The Getty Online Searching Project Report No. 5. Information Processing \& Management, 32(6), 697-707.

Belkin, N. J. (1990). The cognitive viewpoint in information science. Journal of Information Science: Principles and Practice, 16(1), 1116.

Brooks, T. A. (1997). The relevance aura of bibliographic records. Information Processing \& Management, 33(1), 69-80.

Carston, R. \& Uchida, S. (1997). Relevance Theory: Applications and Implications. Philadelphia, PA: John Benjamins Publishing Company.

Caudra, C. A. \& Katter, R. V. (1967). Opening the black box of relevance. Journal of Documentation, 23(4), 291-303.

Copi, I. M. (1982). Introduction to Logic, $6^{\text {th }}$ ed. New York, NY: Macmillan Publishing Co.
Cooper, W. S. (1971). A definition of relevance for information retrieval. Information Storage \& Retrieval, 7, 19-37.

Daniels, P. J. (1986). Cognitive models in information retrieval: An evaluative review. Journal of Documentation, 42(4), 272-304.

Eisenberg, M. B. (1988). Measuring relevance judgments. Information Processing \& Management, 24(4), 373-389.

Ellis, D. (1992). The physical and cognitive paradigms in information retrieval research. Journal of Documentation, 48(1), 45-64.

Fairthorne, R. A. (1958). Summary of Area 6 Discussion. Proceedings of the International Conference on Scientific Information, Washington, DC, 1406.

Foskett, D. J. (1972). A note on the concept of "relevance." Information Storage \& Retrieval, 8, 77-78.

Gluck, M. (1996). Exploring the relationship between user satisfaction and relevance in information systems. Information Processing \& Management, 32(1), 89-104.

Goffman, W. (1964). On relevance as a measure. Information Storage \& Retrieval, 2, 201-203.

Greisdorf, H., \& Spink, A. (1999). Regions of relevance: Approaches to measurement for enhanced precision. Proceedings of the $21^{\text {st }}$ British Computer Society Information Retrieval Sub Group Colloquium (BCS-IRSG) on IR Research, April 19-20, University of Strathclyde, Scotland, UK. (pp. 1-33).

Harter, S. (1992). Psychological relevance and information science. Journal of the American Society for Information Science, 43(9), 602-615.

Helson, H. (1971). Adaptation-level theory: 1970 and after. In Appley, M. H. ed., Adaptation-Level Theory: A Symposium. New York, NY: Academic Press.

Hillman, D. J. (1964). The notion of relevance. American Documentation, January, 26-34.

Howard, D. L. (1994). Pertinence as reflected in personal constructs. Journal of the American Society for Information Science, 45(3), 172-185.

Ingwersen, P. (1996). Cognitive perspectives of information retrieval interaction: Elements of a cognitive IR theory. Journal of Documentation, 52(1), 3-50.

Janes, J. W. (1991). The binary nature of dichotomous relevance judgments: A study of users' perceptions. Journal of the American Society for Information Science, 42(10), 745-756,

Janes, J. W. (1993). On the distribution of relevance judgments. Proceedings of ASIS 93: Annual Meeting of the American Society for Information Science, October 24-28, Columbus, Ohio, 30 (pp. 104114).

Janes, J. W. (1994). Other people's judgments: A comparison of users' and others' judgments of document relevance, topicality and utility. 
Journal of the American Society for Information Science, 45(3), 160-171.

Kelly, G. A. (1955). The psychology of personal constructs (vol. 1). New York: W. W. Norton \& Company, Inc.

Kemp, D. A. (1974). Relevance, pertinence and information system development. Information Storage \& Retrieval, 10, 37-47.

Milech, D. \& Finucane, M. (1998). Decision support and behavioral decision theory. In Implicit and Explicit Mental Processes, Kirsner et. al. (eds.). Mahwah, NJ: Lawrence Erlbaum Associates.

Mizzaro, S. (1998). How many relevances in information retrieval? Interacting with Computers, 10, 303-320.

Morrow, D. \& Greenspan, S. (1989). Situation models and information accessibility. In Sharkey, N. E. (ed.), Models of Cognition: A Review of Cognitive Science. Norwood, NJ: Ablex Publishing Corporation.

O'Connor, J. (1967). Relevance disagreements and unclear request forms. American Documentation, July, 165-177.

O’Neill, R. F. (1960). Theories of Knowledge. Englewood Cliffs, NJ: Prentice Hall, Inc.

Overton, W. F. (1986). Competence and procedures: Constraints on the development of logical reasoning. In Overton, W. F. ed., Reasoning, Necessity, and Logic: Developmental Perspectives. Hillsdale, NJ: Lawrence Erlbaum Associates, Publishers.

Pao, M. L. (1993). Term and citation retrieval: A field study. Information Processing \&Management, 29(1), 95-112.

Park, T. K. (1993). The nature of relevance in information retrieval: an empirical study. Library Quarterly, 63(3), 318-351.

Ricco, R. B. (1986). Necessity and the logic of entailment. In Overton, W. F. ed., Reasoning, Necessity, and Logic: Developmental Perspectives. Hillsdale, NJ: Lawrence Erlbaum Associates, Publishers.

Rees, A. M. (1966). The relevance of relevance to the testing and evaluation of document retrieval systems. Aslib Proceedings, 18(11), 316-324.

Rees, A. M., \& Schultz, D. G. (1967). A field experiment approach to the study of relevance assessments in relation to document searching: Final report. Volume I: Cleveland, OH:CWRU, School of Library Service, Center for Documentation and Communication Research. 305p. NTIS: PB176080.

Saracevic, T. (1969). Comparative effects of titles, abstracts, and full texts on relevance judgments. Proceedings of the American Society for Information Science, vol. 6, 293-299.

Saracevic, T. (1975). Relevance: A review of and a framework for the thinking on the notion in information science. Journal of the American Society for Information Science, 26(6), 321-343.

Saracevic, T., Kantor, P., Chamis, A. Y. \& Trivison, D. (1988). A study of information seeking and retrieving. 1. Background and method- ology. Journal of the American Society for Information Science, 39(3), 161-176.

Schamber, L. (1994). Relevance and information behavior. In M. E. Williams (Ed.), Annual Review of Information Science and Technology, Vol. 29, 3-48. Medford, NJ: American Society for Information Science.

Schamber, L., Eisenberg, M. B., \& Nilan, M. S. (1990). A reexamination of relevance: Toward a dynamic, situational definition. Information Processing \& Management, 26(6), 755-776.

Schutz, A. (1970). Reflections on the Problem of Relevance. New Haven: Yale University Press.

Sperber, D. \& Wilson, D. (1986). Relevance: Communication and Cognition. Cambridge, MA: Harvard University Press.

Spink, A. \& Greisdorf, H. (1997). Users' partial relevance judgments during online searching. Online \& CD-ROM Review, 21(5), 271280 .

Spink, A. \& Greisdorf, H. (1999). How and why end-users make relevance judgments. Proceedings of the $20^{\text {th }}$ National Online Meeting, May, 1999, New York.

Spink, A., Greisdorf, H., \& Bateman, J. (1998a). Examining different regions of relevance: From highly Relevant to not relevant. Proceedings of the Annual Meeting of the American Society for Information Science, Pittsburgh, P.A. October 1998 (pp. 3-12).

Spink, A., Greisdorf, H. \& Bateman, J. (1998b). From highly relevant to not relevant: Examining different regions of relevance. Information Processing \& Management, 34(5), 599-622.

Sternberg, R. J. (1996). Cognitive Psychology. Fort Worth, TX: Harcourt Brace College Publishers.

$\mathrm{Su}, \mathrm{L} . \mathrm{T}$. (1998). Value of search results as a whole as the best single measure of information retrieval performance. Information Processing \& Management, 34(5), 557-579.

Taube, M. (1965). A note on the pseudo-mathematics of relevance. American Documentation, 16(2), 69-72.

Thong, J. Y. L. \& Yap, C. (1996). Information systems effectiveness: A user satisfaction approach. Information Processing \& Management, $32(5), 601-610$

Tiamyu, M. A. \& Ajiferuke, I. Y. (1988). A total relevance and document interaction effects model for the evaluation of information retrieval processes. Information Processing \& Management, 24(4), 391-404.

Wallis, P. \& Thom, J. A. (1996). Relevance judgements for assessing recall. Information Processing \& Management, 32(3), 273-286.

Wilson, P. (1973). Situational relevance. Information Storage \& Retrieval, 9, 457-471. 